\title{
Perceived stress among gravid and its effect on their oral health in Sri Ganganagar, Rajasthan, India
}

\author{
Nikita Goyal*, Simarpreet Singh, Anmol Mathur, Neha Gupta, \\ Diljot K. Makkar, Vikram P. Aggarwal
}

Department of Public Health Dentistry, Surendera Dental College and Research Institute, Sri Ganganagar, Rajasthan, India

Received: 14 January 2017

Accepted: 27 February 2017

\section{*Correspondence:}

Dr. Nikita Goyal,

E-mail: goyal.nikita26@gmail.com

Copyright: () the author(s), publisher and licensee Medip Academy. This is an open-access article distributed under the terms of the Creative Commons Attribution Non-Commercial License, which permits unrestricted non-commercial use, distribution, and reproduction in any medium, provided the original work is properly cited.

\begin{abstract}
Background: The gestation period presents unique stresses that challenges overall psychological adaptation of a women. The present study is designed especially to focus on evaluating the effect of perceived stress on pregnant women and its effect on their oral health.

Methods: A cross-sectional study was conducted among 18-30 years old, pregnant women in the Sri Ganganagar city. Prior to the clinical examination a questionnaire was used in order to collect the information which comprised of three parts and were completed through an interview. The first part comprised of demographics questionnaire, second part included oral hygiene questionnaire and third part was perceived Stress Scale. Descriptive analysis described demographics and socioeconomic characteristics. Multivariate analysis was used to describe the association between stress and various characteristics. Chi-square and Kruskal-wallis test was used to study the association of independent variables with level of stress.

Results: The high stress was reported among those females who were aged $>25$ years $(46.66 \%)$, living in rural areas $(73.33 \%)$, were employed $(57.77 \%)$, were in third trimester of pregnancy $(96.66 \%)$ and had no previous pregnancy experience $(67.77 \%)$. The mothers in high stress group had high levels of dental diseases when compared to the other two groups (low and moderate stress).

Conclusions: Based on the results, this study emphasizes on the need for a continued effort to improve the mental and oral health status of gravid women so as to reduce the incidences of psychological and physical troubles in this population predicted.
\end{abstract}

Keywords: Dental caries, Gravid, Oral health, Stress

\section{INTRODUCTION}

For most women, gravidity is a time of positive expectation, but may also be a period during which the body undergoes major emotional and physiological changes which may also be associated to the onset of alterations in the oral health status. ${ }^{1-3}$ The gestation period presents unique stresses that challenges overall psychological adaptation of a women. Pregnancy may affect some women's life with stress while others may not get affected even when they encounter the most severe and dangerous conditions. ${ }^{1,4}$

Stress can be defined as a state of bodily or mental tension resulting from factors that tend to alter an existent equilibrium. ${ }^{5,6}$ There may be many reasons for maternal stress (perceived stress) such as, preterm birth, risk of gestational hypertension, adverse reproductive health and behavioral outcomes such as high parity, unwanted 
pregnancy, unsafe abortion, infertility and pregnancy complications. Among poor, maternal depression may be related to women's exposure to several depression-related risk factors, including poverty, low social support and domestic violence. ${ }^{1}$

In recent times stress has been widely accepted as a contributing factor for various oral health related diseases. The reason for this can be credited to biological and behavioural mechanisms. The biological mechanism emphasizes how stress and depression can reduce immune system function and facilitate chronic inflammation. These effects are mediated through the production of cortisol, a glucocorticoid capable of reducing immune-competence by inhibiting immunoglobulin $\mathrm{A}$ and $\mathrm{G}$ and neutrophil function, which leads to increased biofilm colonization and reduced ability to prevent connective tissue invasion leading to oral disorders. ${ }^{7}$

The current study used one of the most popular tools for measuring psychological stress i.e., Perceived Stress Scale (PSS; Cohen et al). It is a self-reported questionnaire that was designed to measure the degree to which individuals appraise situations in their lives as stressful. ${ }^{8}$ The pregnancy itself has reported effects towards oral health especially towards periodontal health. Reported gingival inflammation and enlargement during pregnancy. ${ }^{9}$ A case of pregnancy gingivitis was recorded by Pinard in $1877 .{ }^{10}$ The occurrence of pregnancy gingivitis has been reported extremely common, occurring in $30 \%$ to $100 \%$ of all pregnant women. ${ }^{11-13}$

The reason for oral diseases in pregnant women may be attributed to the fact that oral cavity is subjected to reversible as well as irreversible changes due to fluctuations in levels of estrogen and progesterone during pregnancy, leading to dilatation and tortuosity of gingival microvasculature, circulatory stasis and increase in oral vasculature permeability along with a decrease in host immune-competence, thereby increasing susceptibility to oral infections. Beside all the previous literatures and reasoning mentioned the effect of stress cannot be underestimated, in spite of which there is a scarce of studies which relate stress to oral health among pregnant women. Hence, the present study is designed to especially focus on evaluating the effect of perceived stress on pregnant women and its effect on their oral health.

\section{METHODS}

A cross-sectional study was conducted from January to July 2016, among 18-30 years old, pregnant women in the Sri Ganganagar city, Rajasthan, India. The city was divided into four zones, North, South, West and East zone, amongst each zone four Obstetrics and Gynaecology clinics were selected randomly.

A total of 386 gravid women attending the selected clinics who were in the second and third trimester were included in the study. Written informed consent was obtained from all subjects who agreed to take part in the study. A total of 26 pregnant women were excluded from the sample as they were in the first trimester, 37 women were not ready to participate in the study and 17 pregnant women those who had history of systemic diseases such as, hormonal and blood disorders, etc., those taking any medicine (corticosteroids, hormones, etc.) or those who boast any deleterious habits (smoking, drinking etc.) were excluded as well. Therefore, consequences of stress related to biological mechanism were solitarily tested among the remaining 306 gravid women.

Prior to the clinical examination a questionnaire was used in order to collect the information which comprised of three parts and were completed through an interview. The first part was the demographics questionnaire including questions related to patient's age and occupation, the level of patient's education, number of pregnancies, gestational age, and obstetrics risks. The second part included oral hygiene questionnaire which consisted of questions related to materials used for cleaning teeth, frequency of cleaning teeth, visit to dentist, etc.

The third part was perceived Stress Scale (PSS) developed by Cohen et al which helps in evaluating perceived general stress in the past one month. ${ }^{8}$ It evaluates the thoughts and feelings about stressful events, controlling, overcoming, and coping with the experienced stresses. This scale also investigates the risk factors in behavioral disorders and shows the process of stressful relations.

Four-item PSS was selected for this study. In this scale a five-point likert style responses (never, almost never, sometimes, fairly often and very often) were opted for each question. These questions consisted of 2 negatively driven questions (a minimum score of zero and a maximum score of 4 was given to options of never and very often, respectively), and 2 positively driven questions (a minimum score of 4 and a maximum score of 0 were given to options of never and very often, respectively) and then summing across all 4 items. Perceived stress was categorized into low, moderate and high stress on the basis of quartiles.

- Quartile 1 (low stress) ranges from 0 to 4

- Quartile 2 (moderate stress) ranges from 5 to10

- Quartile 3 (high stress) ranges from 11-16

The oral hygiene variables of each subject were assessed using Simplified Oral Hygiene Index (OHI-S) proposed by Greene and Vermillion. ${ }^{14}$ Community periodontal index designed and recommended by WHO and International Dental Federation (FDI), have been used for evaluating periodontal health in this study. ${ }^{15}$ The dental caries was determined by DMFS index (Decayed; Missing; Filled). The index was recommended by Klein and co-authors. ${ }^{16}$ The composition of DMFT and DMFS was studied, in order to clarify which part of the index (filled, decayed or missing) is higher. WHO type III examination was carried out under natural light using. Prior to the study, a team 
made up of four examiners and four pre-trained nursing staff participated in a training program where, inter and intra examiner agreement (Kappa statistics) ranged from 0.77 to 0.95 and from 0.80 to 0.94 respectively, showing a good degree of consistency in the observation. The nursing staff accompanying each examiner was efficient in handling the pregnant women and was trained regarding the questionnaire.

SPSS (statistical package for social sciences) software version 20 was used for statistical analysis. Descriptive analysis described demographics and socioeconomic characteristics. Multivariate analysis was used to describe the association between stress and various characteristics (BPL card holder, professional status, trimester, number of previous pregnancies, complications, DS, DMFS, OHI-S and CPI).

Chi-square and Kruskal-wallis test was used to study the association of independent variables with level of stress. Chi-square test was used to study the association of independent variables (oral hygiene practices, OHI-S and CPI) with level of stress and Kruskal-wallis test was used to study the association of DS, FS, MS and DMFS scores with level of stress. For the ease of multivariate analysis, the CPI categories were dichotomized to good (representing healthy and gingival bleeding and poor representing calculus, shallow periodontal pockets deep periodontal pockets) as well as the OHI-S categories were dichotomized to good and poor (fair, poor).

Statistical significance was defined as $\mathrm{p}<0.05$. World Medical Association Declaration of Helsinki principles for Medical Research involving human subjects were followed to maintain the ethics.

\section{RESULTS}

The study population comprised of 306 pregnant women amongst whom mothers diagnosed with low, moderate and high stress were 48, 168 and 90 respectively. The population in this study was relatively homogenous, based on their demographic and socioeconomic status.

The majorities of the mothers with high stress aged $>25$ years $(46.66 \%)$, lived in rural areas $(73.33 \%)$, were employed $(57.77 \%)$, were in third trimester of pregnancy (96.66\%) and had no previous pregnancy (67.77\%) experience (Table 1).

Table 1: Demographic description of the study population according to the stress.

\begin{tabular}{|c|c|c|c|c|}
\hline Variables & Low stress $\mathbf{N}(\%)$ & Moderate stress N (\%) & High stress $\mathbf{N}(\%)$ & Total N (\%) \\
\hline \multicolumn{5}{|l|}{ Age (Years) } \\
\hline$\leq 20$ & $4(8.33 \%)$ & $13(7.73 \%)$ & $9(10 \%)$ & $26(8.5 \%)$ \\
\hline $20-25$ & $19(39.58 \%)$ & $48(28.57 \%)$ & $39(43.33 \%)$ & $106(34.64 \%)$ \\
\hline$\geq 25$ & $25(52.08 \%)$ & $107(63.69 \%)$ & $42(46.66 \%)$ & $174(56.86 \%)$ \\
\hline \multicolumn{5}{|l|}{ Education } \\
\hline Primary School & $36(75 \%)$ & $106(63.09 \%)$ & $55(61.12 \%)$ & 197 (64.38\%) \\
\hline High School & $7(14.58 \%)$ & $42(25 \%)$ & $28(31.11 \%)$ & 77 (25.16\%) \\
\hline College And Higher & $5(10.41 \%)$ & $20(11.90 \%)$ & $7(7.77 \%)$ & $32(10.45 \%)$ \\
\hline \multicolumn{5}{|l|}{ BPL card holder } \\
\hline Yes & $31(64.58 \%)$ & $76(45.23 \%)$ & $38(42.22 \%)$ & $145(47.38 \%)$ \\
\hline No & $17(35.41 \%)$ & $92(54.76 \%)$ & $52(57.77 \%)$ & $161(52.62 \%)$ \\
\hline \multicolumn{5}{|l|}{ Professional status } \\
\hline Employed & $25(52.08 \%)$ & $101(60.11 \%)$ & $52(57.77 \%)$ & $178(58.16 \%)$ \\
\hline House wife & $23(47.91 \%)$ & $67(39.88 \%)$ & $38(42.22 \%)$ & $128(41.83 \%)$ \\
\hline \multicolumn{5}{|l|}{ Residence } \\
\hline Rural & $27(56.25 \%)$ & $94(55.95 \%)$ & $24(26.66 \%)$ & $145(47.38 \%)$ \\
\hline Urban & $21(43.75 \%)$ & $74(44.04 \%)$ & $66(73.33 \%)$ & $161(52.61 \%)$ \\
\hline \multicolumn{5}{|l|}{ Trimester } \\
\hline Second & $38(79.16 \%)$ & $27(16.07 \%)$ & $3(3.33 \%)$ & $68(22.22 \%)$ \\
\hline Third & $10(20.83 \%)$ & $141(83.92 \%)$ & $87(96.66 \%)$ & $238(77.78 \%)$ \\
\hline \multicolumn{5}{|l|}{ Parity } \\
\hline Primiparous & $14(29.16 \%)$ & $113(67.26 \%)$ & $61(67.77 \%)$ & $188(61.44 \%)$ \\
\hline Multiparous & $34(70.83 \%)$ & $55(32.73 \%)$ & $29(32.22 \%)$ & $118(38.56 \%)$ \\
\hline \multicolumn{5}{|c|}{ Any complication during pregnancy } \\
\hline Yes & $2(4.16 \%)$ & $49(29.16 \%)$ & $53(58.88 \%)$ & $104(33.98 \%)$ \\
\hline No & $46(95.83 \%)$ & $119(70.83 \%)$ & $37(41.11 \%)$ & $202(66.01 \%)$ \\
\hline
\end{tabular}


Table 2: Oral hygiene practices of the study population according to the stress.

\begin{tabular}{|c|c|c|c|c|}
\hline Characteristics & Low Stress N (\%) & Moderate stress N (\%) & High Stress N (\%) & p value \\
\hline \multicolumn{5}{|l|}{ Material used } \\
\hline Tooth paste & $37(77.08 \%)$ & $127(75.59 \%)$ & $67(74.44 \%)$ & \multirow{2}{*}{0.94} \\
\hline Others & $11(22.91 \%)$ & $41(24.40 \%)$ & $23(25.55 \%)$ & \\
\hline \multicolumn{5}{|c|}{ Frequency of cleaning/brushing } \\
\hline Once/Day & $17(35.41 \%)$ & $114(67.85 \%)$ & $58(64.44 \%)$ & \multirow{3}{*}{0.001} \\
\hline Twice/Day & $16(33.33 \%)$ & $22(13.09 \%)$ & $14(15.55 \%)$ & \\
\hline Sometimes & $15(31.25 \%)$ & $32(19.04 \%)$ & $18(20 \%)$ & \\
\hline \multicolumn{5}{|l|}{ Use of Mouth rinses } \\
\hline Yes & $5(10.41 \%)$ & $20(11.90 \%)$ & $7(7.77 \%)$ & \multirow{2}{*}{0.59} \\
\hline No & $43(89.58 \%)$ & $148(88.09 \%)$ & $83(92.22 \%)$ & \\
\hline \multicolumn{5}{|c|}{ Use of fluoridated toothpaste } \\
\hline Yes & $44(91.66 \%)$ & $139(82.73 \%)$ & $79(87.77 \%)$ & \multirow[b]{2}{*}{0.24} \\
\hline No & $4(8.33 \%)$ & $29(17.26 \%)$ & $11(12.22 \%)$ & \\
\hline \multicolumn{5}{|l|}{ Visit to dentist } \\
\hline At regular intervals & $2(4.16 \%)$ & $12(7.14 \%)$ & $6(6.66 \%)$ & \multirow{3}{*}{0.03} \\
\hline Only when required & $1(2.08 \%)$ & $33(19.64 \%)$ & $20(22.22 \%)$ & \\
\hline Never & $45(93.75 \%)$ & $123(73.21 \%)$ & $64(71.11 \%)$ & \\
\hline \multicolumn{5}{|c|}{ Self-reported oral health } \\
\hline Good & $15(31.25 \%)$ & $48(28.57 \%)$ & $19(21.11 \%)$ & \multirow{3}{*}{0.003} \\
\hline Fair & $16(33.33 \%)$ & $90(53.57 \%)$ & $59(65.55 \%)$ & \\
\hline Poor & $17(35.41 \%)$ & $30(17.85 \%)$ & $12(13.33 \%)$ & \\
\hline
\end{tabular}

Table 3: Mean stress scores among pregnant women according various oral health disorders.

\begin{tabular}{|lllll|}
\hline Dental Disorders & Low stress mean (SD) & Moderate stress mean (SD) & High stress mean (SD) & p value \\
\hline DS & $1.92^{\mathrm{a}}(1.72)$ & $2.71^{\mathrm{b}}(2.34)$ & $3.76^{\mathrm{c}}(3.46)$ & $<0.01$ \\
\hline MS & $0.19^{\mathrm{a}}(0.82)$ & $1.26^{\mathrm{b}}(2.07)$ & $1^{\mathrm{b}}(1.99)$ & $<0.01$ \\
\hline FS & $0.33^{\mathrm{a}}(1.12)$ & $0^{\mathrm{b}}$ & $0^{\mathrm{b}}$ & $<0.01$ \\
\hline DMFS & $2.44^{\mathrm{a}}(2.46)$ & $3.97^{\mathrm{b}}(3.68)$ & $4.76^{\mathrm{c}}(4.43)$ & \\
\hline OHI-S & $\mathrm{N} \%$ & $\mathrm{~N}(\%)$ & $\mathrm{N}(\%)$ & \\
\hline Good & $11(22.91 \%)$ & $11(6.54 \%)$ & $5(5.55 \%)$ & \\
\hline Fair & $30(62.5 \%)$ & $102(60.71 \%)$ & $46(51.11 \%)$ & \\
\hline Poor & $7(14.58 \%)$ & $55(32.73 \%)$ & $39(43.33 \%)$ & \\
\hline CPI & $\mathrm{N} \%$ & $\mathrm{~N}(\%)$ & $\mathrm{N}(\%)$ & \\
\hline 0 & $9(18.75 \%)$ & $4(2.38 \%)$ & $1(1.11 \%)$ & \\
\hline 1 & $2(4.16 \%)$ & $32(19.04 \%)$ & $17(18.88 \%)$ & \\
\hline 2 & $24(50 \%)$ & $59(35.11 \%)$ & $32(35.55 \%)$ & \\
\hline 3 & $10(20.83 \%)$ & $58(34.52 \%)$ & $31(34.44 \%)$ & \\
\hline 4 & $2(4.16 \%)$ & $15(8.92 \%)$ & $9(10 \%)$ & \\
\hline
\end{tabular}

Most of the women used toothpaste $(75.49 \%)$, brushed once daily $(61.76 \%)$, never visited the dentist $(75.81 \%)$ and fair $(53.92 \%)$ self-reported oral health (Table 2).

The mothers in high stress group had high levels of dental diseases when compared to the other two groups (low and moderate stress) based on DMFS, OHI-S and CPI index. The women with high stress had more mean DMFS score (4.76) and poor OHI-S score (43.33\%). The CPI index measured that women with moderate and high stress experienced more periodontal diseases as compared to the low stress women (Table 3).
Trimesters, previous pregnancies and complications showed significant results in relation to moderate and high stress ( $\mathrm{P}$ value <0.0001) whereas DS, DMFS, OHI-S showed association with higher level of stress, which was tested using multivariate analysis (Table 4). The majorities of the mothers with high stress aged $>25$ years $(46.66 \%)$, lived in rural areas $(73.33 \%)$, were employed $(57.77 \%)$, were in third trimester of pregnancy $(96.66 \%)$ and had no previous pregnancy (67.77\%) experience (Table 1). Most of the women used toothpaste $(75.49 \%)$, brushed once daily $(61.76 \%)$, never visited the dentist $(75.81 \%)$ and fair (53.92\%) self-reported oral health (Table 2). 
Table 4: Multivariate analysis with stress as dependent variable.

\begin{tabular}{|llll|}
\hline Characteristics & Low stress & Moderate stress & High stress \\
\hline BPL card holder & Ref & $2.21(1.14-4.29)$ & $2.49(1.21-5.15)$ \\
\hline & & 0.02 & 0.01 \\
\hline Professional status & Ref & $1.39(0.72-2.64)$ & $1.26(0.62-2.55)$ \\
\hline & & 0.32 & 0.52 \\
\hline Trimester & Ref & $19.84(8.84-44.57)$ & $110(28.70-423.11)$ \\
\hline & & $<0.0001$ & $<0.0001$ \\
\hline No. of previous pregnancies & Ref & $4.99(2.48-10.06)$ & $5.10(2.38-10.96)$ \\
\hline & & $<0.0001$ & $<0.0001$ \\
\hline Complications & Ref & $55.86(13.05-239.15)$ & $32.95(7.52-144.25)$ \\
\hline & & $<0.0001$ & $<0.0001$ \\
\hline DS & Ref & $3.32(1.67-6.57)$ & $7.23(3.31-15.80)$ \\
\hline & & 0.0006 & $<0.0001$ \\
\hline DMFS & Ref & $3.97(2.81-6.98)$ & $4.31(3.98-17.07)$ \\
\hline & & 0.0002 & $<0.0001$ \\
\hline OHI-S & Ref & $4.24(1.71-10.53)$ & $5.05(1.64-15.57)$ \\
\hline & & 0.001 & 0.004 \\
\hline CPI & Ref & $8.25(2.40-28.34)$ & $18(2.19-147.64)$ \\
\hline & & 0.0008 & 0.007 \\
\hline
\end{tabular}

The mothers in high stress group had high levels of dental diseases when compared to the other two groups (low and moderate stress) based on DMFS, OHI-S and CPI index. The women with high stress had more mean DMFS score (4.76) and poor OHI-S score $(43.33 \%)$. The CPI index measured that women with moderate and high stress experienced more periodontal diseases as compared to the low stress women (Table 3). Trimesters, previous pregnancies and complications showed significant results in relation to moderate and high stress ( $\mathrm{P}$ value $<0.0001$ ) whereas DS, DMFS, OHI-S showed association with higher level of stress, which was tested using multivariate analysis (Table 4).

\section{DISCUSSION}

Preeclampsia leads to increased perinatal morbidity and The health and disease care process for the oral component is a complex association of factors that interact in various ways among different social groups and these different groups within the same society have different disease profiles, categories and incidence. Hence, the present study is being focused on a special segment of the population in a marked area, considering conditions of vulnerability: being gravid and stressed. This study is a pioneer attempt to assess the effect of stress during pregnancy on oral health status. Large proportion of the population in this study belonged to the age group of $>25$ years $(56.86 \%)$, are in their third trimester of pregnancy period $(77.78 \%)$, were primiparous $(61.44 \%)$,illiterate (46.07\%), employed (57.77\%) and resident of urban area $(52.61 \%)$. The chief focus of this discussion is on the outcome of stress on gravid's oral health. Though, there is hardly any literature on this association, rendering it difficult to discuss and compare, still an attempt in this aspect has been made through this discussion. Among the females who reported with low stress (48) maximum belonged to below poverty category $(64.58 \%)$ with BPL card. This is in contradiction with other studies where poor population was found to be more stressed. ${ }^{17-22}$ According to the authors the reason for low stress among pregnant women with low socio-economic status might be attributed to the fact that they are accustomed to harsh and challenging circumstances, making them more adaptive and efficient during maternal period as compared to the group of women with high socio-economic status whose routine life is simpler than their maternal period.

Studies by Marcus SM et al and Srinivasan N et al have shown no significant difference in relation to stress among primiparous and multiparous which was contrasting with the present study where high stress is more prevalent among primiparous women $(67.77 \%) .{ }^{18,23}$ Justification to these results could be that with the progression in pregnancy, physical changes associated with anxiety regarding labor and fetal outcomes or worries about changes in their personal life due to first pregnancy and child birth potentially worsen the stress response and lead pregnant women to have greater discomfort. Study by Marcus SM et al described that women who were unemployed were related to elevated symptoms of depression during pregnancy. ${ }^{18}$ But, according to the results of the present study, high stress level was revealed to be more in women who are employed $(57.77 \%)$ which is similar to studies by Desai S et al and Homer CJ et al. ${ }^{24,25}$ Reason might be that, women has to choose between employment and maternity, making them economically vulnerable. Pregnancy may also raise the cost of living for 
the women, what economists call the shadow price of time in the home, i.e., the value to the family of women's time in homemaking leading women to high stress.

This research found that more number of gravid women dwelling in rural communities were less stressed $(56.25 \%)$ as compared to those from urban communities $(43.75 \%)$ this pattern of results is being supported by many other studies. $^{26-31}$ On contrary, few studies found that rural residence might be associated with high stress. ${ }^{32,33}$ Yet other studies found no significant relationship between depression and place of residence. ${ }^{30,34}$ The cause for low stress in rural women according to the authors might be due to the fact that, people in rural communities are more likely than their urban counterparts to live in joint family structure, which will provide necessary support to the female in this vulnerable state. According to the results of current study, the women who were in third trimester were highly stressed $(96.66 \%)$ as compared to the women in second trimester $(3.33 \%)$ and the same was reported by Teixeira $\mathrm{C}$ et al. ${ }^{35}$ This pattern of extraordinary higher risk present in women from third trimester might be due to delivery propinquity, which is more feared and requires superfluous preparation. Although oral health problems are common during pregnancy, little is known about the individual characteristics or behaviors relating to clinically assessed oral health during pregnancy and this study further discusses about the possible reasons for the same. Stress is one major factor whose effect is never being tested towards oral health among pregnant women and this study is a sincere attempt towards this untouched aspect.

The present study found a significant association of perceived stress with dental disorders as shown in table 3 $(p \leq 0.05)$. The biologic plausibility for such a union is supported by various studies. ${ }^{23,36,37}$ All these crosssectional studies emphasized towards the progressive association of psychosocial stress with periodontal diseases but, the multivariate analysis conducted in the present study (Table 4) revealed that stress has its utmost impact towards dental caries when compared with periodontal diseases and this is being considered to be the most important finding by the current study. The relationship between stress and dental caries has rarely been studied, maybe due to the fact that caries is considered as an infectious disease.

According to the authors of this investigation, the possible explanation for the association between stress and dental caries can be, detrimental emotional eating habits leading to frequent snacking and more intake of sugar containing diet. Consumption of these foods or beverages in between meals may promote dental caries. An additional reason can be due to the impaired performance of self-care habits (frequency of brushing teeth) leading to poor oral hygiene creating favorable environment for bacteria. It can also be due to the reduced salivary secretion leading to decreased clearance of cariogenic bacteria as; subjective oral dryness and unstimulated salivary flow were significantly associated with perceived stress affecting hard tooth structure leading to dental decay.

Pregnancy is a very crucial period not only for mother or baby but for the entire family. By virtue of this study a high frequency of depression was found among the study subjects during pregnancy, having no history of stress in their lifetime. Along with this a high prevalence of dental disorders is being established among pregnant women, which can not only be linked to hormonal changes during pregnancy but must also be associated with the perceived maternal stress. Hence, this study emphasizes on the need for a continued effort to improve the mental and oral health status of gravid women so as to reduce the incidences of psychological and physical troubles in this population.

Funding: No funding sources

Conflict of interest: None declared

Ethical approval: The study was approved by the Institutional Ethics Committee

\section{REFERENCES}

1. Iranzad I, Bani S, Hasanpour S, Mohammadalizadeh S, Mirghafourvand M. Perceived Social Support and Stress among Pregnant Women at Health Centers of Iran- Tabriz. J Caring Sci. 2014; 3(4): 287-95.

2. Cornejo C. Oral health status and oral health-related quality of life in pregnant women from socially deprived populations. Acta Odontol Latinoam 2013;26:68-74.

3. Couto ER, Couto E, Vian B, Gregório Z, Nomura ML, Zaccaria R. Quality of life, depression and anxiety among pregnant women with previous adverse pregnancy outcomes. Sao Paulo Med. J 2009;127(4):185-9.

4. Repetti RL, Taylor SE, Seeman TE. Risky families: family social environments and the mental and physical health of offspring. Psychol Bull. 2002;128(2):330-60.

5. Kalra S, Einarson A, Karaskov T, Uum SV, Koren G. The relationship between stress and hair cortisol in healthy pregnant women. Clin Invest Med. 2007;30(2):103-7.

6. De Weerth C, Buitelaar JK. Physiological stress reactivity in human pregnancy-a review. Neurosci Biobehav Rev. 2005;29:295-312.

7. Malathi K, Sabale D. Stress and periodontitis: A review. IOSR J Dent Med Sci. 2013;9(4):54-7.

8. Cohen S, Kamarck T, Mermelstein R. A global measure of perceived stress. J Health Soc Behav.1983;24:385-96.

9. Pitcairn J. A case of disease of the gams (that) occurred during pregnancy. Hosp Rep. 1818;2:309.

10. Pinard A. Gingivitis in pregnancy. Dent Register. 1877;31:258.

11. Samant A, Malik CP, Chabar SK, Devi PK. Gingivitis and Periodontal disease in pregnancy. J Clin Periodontal. 1976;47:415-8. 
12. Raber- Durlacher JE, Van steenbergen TJ, Van Der Relden U. Expenmental gingivitis during Pregnancy and postpartum: Clinical endocrinological and microbiological aspects. J Clin Periodontal. 1994;21:549.

13. Yaghobi S, Haghighati F. Evaluation of the oral health status and needs for periodontal treatment in pregnant women. Avicenna J Dent Res. 2010;2(1):53-8.

14. Greene JC, Vermillion JR. The simplified oral hygiene index. J Am Dent Assoc. 1964;68:7-13.

15. Community Periodontal Index. World Health Organization. Oral health surveys: basic methods. 4th ed. Geneva: WHO;1997:36-8.

16. Klein H, Palmer C, Knutson JW. Studies of dental caries I: dental status and dental needs of elementary school children. Public Health Rep. 1938;53:751-65.

17. Vijayaselvi R, Beck MM, Abraham A, Kurian S, Regi A, Rebekah G. Risk factors for stress during antenatal period among pregnant women in tertiary care hospital of Southern India. J Clin Diagn Res. 2015;9(10):1-5.

18. Marcus SM, Flynn HA, Blow FC, Barry KL. Depressive symptoms among pregnant women screened in obstetrics settings. J Women's Health. 2003;12(4):373-380.

19. Glazier RH, Elgar FJ, Goel V, Holzapfel S. Stress, social support, and emotional distress in a community sample of pregnant women. J Psychosom Obstet Gynecol. 2004;25:247-55.

20. Turner RJ, Frankel BG, Levin DM. Social support: Conceptualization, measurement and implications for mental health. Res Community Ment Health. 1983;3:67-111.

21. Turner RJ, Lloyd DA. The stress process and the social distribution of depression. J Health Soc Behav. 1999;40:374-404.

22. Bolton HL, Hughes PM, Turton P, Sedgwick P. Incidence and demographic correlates of depressive symptoms during pregnancy in an inner city London population. J Psychosom Obstet Gynaecol. 1998;19:202.

23. Srinivasan N, Murthy S, Singh AK, Upadhyay V, Mohan SK, Joshi A. Assessment of burden of depression during pregnancy among pregnant women residing in rural setting of Chennai. J Clin Diagn Res. 2015;9(4):8-12.

24. Desai S, Waite LJ. Women's employment during pregnancy and after the first birth: occupational characteristics and work commitment. Am Sociol Rev. 1991;56:551-66.

25. Homer CJ, James SA, Siegel E. Work-related psychosocial stress and risk of preterm, low birthweight delivery. Am J Public Health. 1990;80:173-7.

26. Peruzzo DC1, Benatti BB, Ambrosano GM, Nogueira-Filho GR, Sallum EA, Casati MZ et al. A systematic review of stress and psychological factors as possible risk factors for periodontal disease. J Periodontol. 2007;78(8):1491-504.

27. Logrippo MT. The relationship of perceived trust and perceived stress among pregnant women receiving care from a certified nurse midwife: Seton Hall University Dissertations and Theses (ETDs);2013. Available from: http://scholarship.shu.edu/cgi/viewcontent.cgi?article $=2863 \&$ context $=$ dissertations.

28. Wang JL. Rural-urban differences in the prevalence of major depression and associated impairment. Soc Psychiatry Psychiatr Epidemiol. 2004;39(1):19-25.

29. Hillemeier MM, Weisman CS, Chase GA, Dyer AM. Mental health status among rural women of reproductive age: findings from the Central Pennsylvania Women's Health Study. Am J Public Health. 2008;98(7):1271-9.

30. Blazer D, George LK, Landerman R, Pennybacker M, Melville ML, Woodbury M, Manton KG et al. Psychiatric disorders. A rural/urban comparison. Arch Gen Psychiatry 1985;42(7):651-6.

31. Villegas L, McKay K, Dennis CL, Ross LE. Postpartum depression among rural women from developed and developing countries: a systematic review. J Rural Health. 2011;27:278-88.

32. Jesse DE, Dolbier CL, Blanchard A. Barriers to seeking help and treatment suggestions for prenatal depressive symptoms: focus groups with rural lowincome women. Issues Ment Health Nurs. 2008;29(1):3-19.

33. Hoyt DR, Conger RD, Valde JG, Weihs K. Psychological distress and help seeking in rural America. Am J Community Psychol. 1997;25(4):44970.

34. Kerby J. How stressed are rural people? Rural Soc. 1992;2:15-17.

35. Teixeira C, Figueiredo B, Conde A, Pacheco A, Costa R. Anxiety and depression during pregnancy in women and men. J Affect Disord. 2009;119:142-8.

36. Sam KSN, Leung WK. A community study on the relationship between stress, coping, affective dispositions and periodontal attachment loss. Community Dent Oral Epidemiol. 2006;34:252-66.

37. Abdollahi F, Rohani S, Sazlina GS. Bio-psychosocio-demographic and obstetric predictors of postpartum depression in pregnancy: a prospective cohort study. Iran J Psychiatry Behav Sci. 2014;8(2):11-21.

Cite this article as: Goyal N, Singh S, Mathur A, Gupta N, Makkar DK, Aggarwal VP. Perceived stress among gravid and its effect on their oral health in Sri Ganganagar, Rajasthan, India. Int J Reprod Contracept Obstet Gynecol 2017;6:1381-7. 